\title{
Necessidades de Interface para Facilitar a Colaboração em Ambientes Virtuais de Aprendizagem
}

\author{
Interface Needs to Facilitate Collaboration in Learning Management Systems
}

GUGLIANO, Bruna Ferreira; Mestre; Universidade Federal do Rio Grande do Sul

brunafgugliano@gmail.com

DA SILVA, Régio Pierre; Doutor; Universidade Federal do Rio Grande do Sul

regio@ufrgs.br

\section{Resumo}

O crescente uso das tecnologias digitais no dia-a-dia dos indivíduos gerou diversas mudanças de comportamento, como as tendências colaborativas de troca e compartilhamento de informações. Essas tendências passam a integrar não apenas a vida social dos usuários da internet, mas também surgem no ambiente escolar e de trabalho, mediadas por diferentes interfaces e dispositivos digitais. Neste artigo pretende-se identificar características de interfaces colaborativas, relacionálas com conhecimentos da área de design de interfaces, definindo necessidades a serem consideradas no projeto de ambientes virtuais de aprendizagem (AVAs). Para tal, apresenta-se uma revisão bibliográfica a respeito da colaboração nos ambientes virtuais de aprendizagem, seguida de uma descrição, com análise de similares, dos mecanismos de conversação, coordenação e percepção, resultando em uma listagem contendo necessidades de interface para facilitar a colaboração em AVAs.

Palavras Chave: design de interfaces; colaboração; ambientes virtuais de aprendizagem.

\begin{abstract}
The increasing use of digital technologies in day-to-day life of individuals generated several behavioral changes, such as collaborative trends of exchange and sharing of information. These trends not only become part of the social life of Internet users, but also arise at school and work, mediated by different interfaces and digital devices. This paper aims to identify the characteristics of collaborative interfaces, relating them to interface design topics, defining needs to be considered in the design of learning management systems (LMS). For this, a literature review about the collaboration in learning management systems is presented, followed by a description, with similar analysis, of the mechanisms of conversation, coordination and awareness, resulting in a list containing interface needs to facilitate collaboration in LMS.
\end{abstract}

Keywords: interface design; collaboration; learning management system. 


\section{Introdução}

Foi num período de poucas décadas a partir da invenção das tecnologias digitais que bilhões de pessoas passaram a adotar as novas ferramentas de comunicação (PALFREY; GASSER, 2011). O uso dessas tecnologias não ocorre de maneira passiva; o usuário da internet, na maioria das vezes, participa ativamente na criação e difusão de dados através de blogs, sites de redes sociais e plataformas de compartilhamento de arquivos. Reunindo-se nesses ambientes, pessoas com diversas experiências de vida podem partilhar do seu conhecimento de forma rápida e prática, sem sair de suas casas (BOTSMAN; ROGERS, 2011).

Neste contexto, há um crescente interesse nas pesquisas em educação a respeito das formas de ensinar e aprender através da internet (CARDOSO; MATOS, 2012), que caminha em direção a uma adequação das tecnologias educacionais às tendências colaborativas normalmente vistas nas redes sociais. No entanto, Hamuy e Galaz (2010) constataram que as plataformas educacionais acabam sendo utilizadas mais como repositórios de informação que como ambientes para troca de ideias.

Por isso, é importante projetar sistemas interativos que suportem as diversas formas de socialização de modo a auxiliar o andamento de processos colaborativos, verificando as tecnologias existentes e examinando maneiras de aprimorá-las para melhor atender às necessidades dos usuários dessas plataformas (PREECE; ROGERS; SHARP, 2005).

Este artigo está baseado em pesquisa de mestrado desenvolvida na pós-graduação em Design da Universidade Federal do Rio Grande do Sul (PGDESIGN/UFRGS), cuja pretensão foi compreender como as ferramentas que surgiram a partir do uso das tecnologias digitais facilitaram a colaboração entre usuários na internet. Já o objetivo deste artigo é, em especial, ao identificar características de interfaces colaborativas, relacioná-las com conhecimentos da área de design digital, definindo necessidades a serem consideradas no projeto de ambientes virtuais de aprendizagem. É importante salientar que se considera que a revisão realizada e os resultados alcançados são adequados para aplicação em outros ambientes virtuais que não sejam de aprendizagem, com os devidos ajustes.

Para alcançar o objetivo descrito, é apresentada primeiramente uma revisão bibliográfica a respeito da colaboração nos ambientes virtuais de aprendizagem, seguida de uma descrição, com análise de similares, dos chamados "mecanismos de colaboração" e da listagem de necessidades de interface para facilitar a colaboração nos ambientes de aprendizagem citados. Na conclusão indica-se a relevância desse tipo de estudo, com a finalidade de evidenciar a importância do design de interfaces no auxílio à colaboração nas atividades realizadas em plataformas educacionais.

\section{A Colaboração nos Ambientes Virtuais de Aprendizagem}

Para Troncarelli e Faria (2014), existe uma exigência cada vez maior por parte dos alunos de participar, colaborar e opinar durante as aulas e em questões administrativas das instituições de ensino. Essa mudança de perfil dos alunos pode ter ocorrido considerando o acesso facilitado às informações, potencializado pelo avanço das tecnologias digitais. Segundo Lévy, usuários reúnem-se virtualmente em ambientes alimentados e construídos "sobre as afinidades de interesses, de conhecimentos, sobre projetos mútuos, em um processo de cooperação ou de troca, tudo isso independentemente das proximidades geográficas e das filiações institucionais" 
(2010, p. 130).

A utilização das redes como um meio para a aprendizagem é uma das maiores mudanças perceptíveis no campo da educação da atualidade. No entanto, esta mudança não implica somente no uso dos ambientes virtuais de aprendizagem, mas também no estabelecimento de meios que possibilitem a participação e o envolvimento dos usuários, de modo que seja possível desenvolver a capacidade de realizar atividades em conjunto e pensar de forma colaborativa (DIAS, 2013).

Ambientes virtuais de aprendizagem, ou AVAs, são espaços virtuais onde estudantes, professores, tutores e demais atores envolvidos no processo educacional interagem e compartilham conteúdos que servem como suporte para a aprendizagem (ALARCON; SPANHOL, 2015). Segundo a Associação Brasileira de Educação a Distância ${ }^{1}$, em 2016, $91 \%$ dos órgãos públicos e $78 \%$ das instituições privadas com fins lucrativos utilizavam AVAs para distribuir seus conteúdos. Ainda de acordo com a pesquisa, $79 \%$ dos cursos regulamentados totalmente a distância usufruíram do mesmo recurso. De acordo com Filatro e Cairo (2015), as funcionalidades presentes nos AVAs podem ser distribuídas em três grupos:

- Coordenação: ferramentas que permitem organizar os conteúdos.

- Administração: ferramentas que permitem gerenciar usuários, acessos, configurações e prazos.

- Comunicação: ferramentas que possibilitam a comunicação entre usuários, tanto estudantes quanto professores.

Os AVAs podem ser encontrados nas modalidades comerciais e gratuitas. Segundo Mattar (2014), as principais plataformas pagas são Blackboard, WebCT e Angel. Já as gratuitas mais utilizadas no Brasil são Moodle, Sakai, TelEduc e AulaNet, sendo o primeiro exemplo o mais comum nas instituições de ensino. Nas estatísticas do site oficial do Moodle ${ }^{2}$ constam 5.178 sites registrados no Brasil que utilizam a plataforma. Para Imran et al (2016), tanto o Moodle quanto o Blackboard disponibilizam as mesmas ferramentas de colaboração social e criação de redes, como: fóruns de discussão, wikis, blogs, chats, quizzes, salas de aula virtuais, integração do Twitter e Facebook, avaliação por pares e envio de mensagens de celular.

Para Silva (2016), o sucesso do Moodle deve-se ao foco que a plataforma dá para atividades e metodologias socioconstrutivistas, nas quais as ações colaborativas cumprem um importante papel, "privilegiando a construção/reconstrução do conhecimento, a autoria, a produção de conhecimento em colaboração com os pares e a aprendizagem significativa do aluno" (p. 17).

Cavalcanti (2014) relata que - em pesquisa cuja metodologia utilizou entrevistas e grupos focais -, apesar do Moodle apresentar ferramentas para a conversação entre os usuários (chat, fórum, videoconferência), estas são utilizadas como recurso pedagógico para atividades específicas, não podendo ser acessadas livremente. Por isso, os estudantes consultados pela autora acabam por utilizar outras ferramentas para desenvolver seus projetos, como as disponíveis no Facebook e no Skype. A autora salienta também que a interface gráfica e as

\footnotetext{
${ }^{1}$ Disponível em: < http://abed.org.br/censoead2016/Censo_EAD_2016_portugues.pdf> Acesso em: 14 mar. 2018.

${ }^{2}$ Dados disponíveis em: <https://moodle.net/stats/>. Acesso em: 14 jun. 2018.
} 
interações disponíveis em sites de redes sociais como o Facebook são mais agradáveis do que as presentes no Moodle, sendo este um dos fatores para a escolha do uso dessa ferramenta.

O ensino de práticas colaborativas em sala de aula também ajuda a preparar o aluno para as dinâmicas de trabalho em sua futura vida profissional, como afirmam Palfrey e Gasser (2011, p. 278): "Enquanto os alunos pesquisam, escrevem e criam colaborativamente através dos ambientes online, eles estão aprendendo habilidades que vão lhes servir muito no decorrer do tempo, à medida que a economia digital se desenvolve".

Para Lowyck e Poisa (2001), o grau em que o ambiente é percebido como interativo tem influência na eficácia do sistema. No caso dos ambientes colaborativos, em que a participação de todos deve ser motivada, a relevância das interações é ainda maior. A definição dessas propriedades - uma das competências do profissional de design - determina, também, o tipo de informação e a maneira como ela será transmitida.

Não basta apenas colocar à disposição uma série de ferramentas; é necessário que haja interesses compartilhados, intimidade, perenidade nas relações. É isso que vai diferenciar uma comunidade mediada por computadores de uma simples agregação eletrônica. É preciso motivação para que uma comunidade continue com vigor e intensidade, mesmo levando em conta a ausência de contato corporal e a distância geográfica (LEMOS; LEVY, 2010, p. 103).

É papel do designer de interfaces pensar os meios para gerar essa motivação nos estudantes e demais usuários dos AVAs. Para Portugal (2013, p. 61), "o Design tem a função social de tornar o ambiente inteligível, possibilitando nossa ação a partir dos signos e da construção da legibilidade do discurso comunicativo nos ambientes, sejam eles digitais ou não".

Uma interface bem projetada possibilita que tanto a estrutura quanto as interações possíveis no face-a-face se mantenham em um ambiente virtual (HORTON, 2011). Como já comentado, a participação é essencial em uma rede virtual de colaboração. Para alcançar esse objetivo, a interface deve apresentar ferramentas colaborativas de forma clara e acessível. Segundo Peters (2013), a dificuldade no uso das interfaces é um dos principais motivos da falta de envolvimento dos usuários. Por isso, ela deve ser considerada desde o início do projeto, do contrário, sua necessidade pode ser percebida quando a interface já estiver em uso, gerando frustração no usuário e novas demandas para a equipe de desenvolvimento. Como salienta Manzini:

(...) quanto menos habilidoso o usuário, mais o sistema deve ser capaz de compensar sua carência de habilidades, fornecendo o que ele não sabe ou não pode fazer. Além disso, quanto menos motivado for o usuário, mais o sistema deve ser não apenas amigável, mas também atraente, ou seja, participar ativamente de uma organização colaborativa deve ser considerado estimulante (2008, p. 85).

Os projetos de interfaces devem, portanto, estimular e desenvolver as habilidades de seus usuários, considerando as capacidades individuais de cada um. Se o usuário for mais experiente, a solução poderá ser simples; já se o usuário tiver menos habilidade ou motivação no acesso, essa carência deverá ser compensada pelo sistema, demonstrando de forma clara os caminhos a serem seguidos.

\section{Os Mecanismos de Colaboração}

Preece, Rogers e Sharp (2005) descrevem três categorias que consideram essenciais para a 
colaboração, e como o designer pode trabalhar para facilitá-las. São elas: mecanismos de conversação, mecanismos de coordenação e mecanismos de percepção. Outros pesquisadores, apesar de não utilizarem a mesma nomenclatura, também sugerem ferramentas e elementos de interface que se ajustam a essas categorias, e serão incluídos nessa seção. Essas propostas focam em soluções visuais, que influenciam a percepção do usuário, muito marcado por representações como fotos, ilustrações, diagramas, ícones, etc. (BÜRDEK, 2010).

\subsection{Mecanismos de Conversação}

Segundo Primo et al (2016), apesar das tecnologias digitais já terem sido tratadas, devido à ausência do face-a-face, "como formas limitadas de comunicação e relacionamento em virtude da menor disponibilidade de pistas não-verbais" (p. 5), indivíduos as utilizam cada vez mais para interagir com seus pares, tanto no contexto pessoal (amigos, familiares), quanto no profissional (colegas de trabalho, de universidade). Assim, é importante que a interface forneça os mecanismos de conversação necessários para uma comunicação com o mínimo de falhas.

O quadro 1, adaptado de Horton (2011), apresenta diferentes graus de comunicação relacionados a diferentes mídias, ou seja, qual tipo de recurso tecnológico pode ser utilizado de acordo com a necessidade comunicacional.

Quadro 1 - grau de comunicação x mídia a ser utilizada

\begin{tabular}{lll}
\hline Linguagem corporal & Expressões faciais & Videoconferência em alta resolução \\
\cline { 2 - 3 } & Gestos e posturas & Videoconferência em baixa resolução \\
\hline Palavra falada & Tom e ênfases & Audioconferência em alta resolução \\
\cline { 2 - 3 } & Ritmo & Audioconferência em baixa resolução \\
\hline Palavra escrita & Síncrona em dois sentidos & Chats e mensagens instantâneas \\
\cline { 2 - 3 } & Assíncrona em dois sentidos & Fóruns de discussão e e-mails \\
\cline { 2 - 3 } & Em um sentido & Páginas web e blogs \\
\hline
\end{tabular}

Fonte: adaptado de HORTON, 2011, p. 422.

No mundo "real", mesmo que não se perceba, conversas possuem regras préestabelecidas. Quando falhas de comunicação ocorrem, os interlocutores se utilizam de mecanismos para repará-las, como mudar o tom da voz, repetir de forma mais clara e utilizar gestos ou expressões faciais. Nos ambientes virtuais nem todos esses mecanismos estão disponíveis (HRON; FRIEDRICH, 2003). Por isso, é trabalho do designer facilitar e desenvolver diferentes tipos de conversação e formas de reparar falhas: "um dos desafios que os designers enfrentam é considerar como os diferentes tipos de comunicação podem ser facilitados e apoiados em ambientes onde há a possibilidade de existirem obstáculos que a impeçam de acontecer 'naturalmente'" (PREECE; ROGERS; SHARP, 2005, p. 130).

O software Skype, por exemplo (figura 1), apresenta diversos recursos para facilitar a conversação, como a conversa síncrona (chat), por vídeo (videoconferência) ou somente por áudio (audioconferência). Além desses recursos, o Skype fornece suporte para o envio de arquivos, imagens, emojis, entre outros. Emojis, ou emoticons, representam diversas emoções que não podem ser percebidas apenas na linguagem escrita. 
Figura 1 - interface da janela de chat do Skype
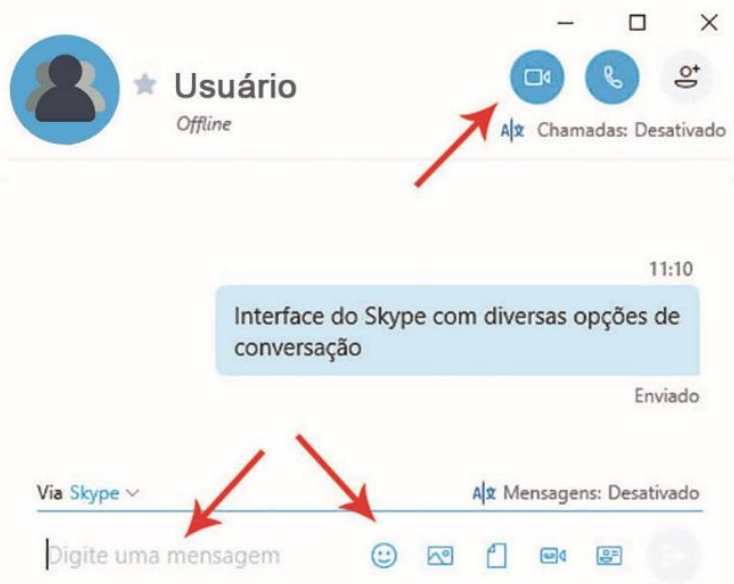

Fonte: simulado pela autora em janela do Skype.

Presencialmente, em conversas que envolvem muitas pessoas, é utilizado o toque ou a menção do nome do interlocutor ao qual se está referindo. Virtualmente, referências diretas a alguém podem se perder em meio às conversas. Os principais sites e aplicativos de redes sociais, como Facebook, Twitter, Instagram e Whatsapp utilizam a função "mencionar", que permite notificar um usuário específico em um grupo digitando o caractere “@” antes do nome do destinatário. O recurso facilita, por exemplo, quando é necessário fazer uma questão diretamente a alguém, ou distribuir tarefas.

Alguns recursos podem ser utilizados para que os usuários se expressem sem necessariamente dialogar entre si, como as caixas de comentários, os depoimentos, as avaliações de utilidade e a possibilidade de compartilhar e de avaliar conteúdo. Para Alves e Barbosa, "o compartilhamento está diretamente relacionado com as trocas de informação baseadas na vontade do indivíduo em contribuir, mesmo quando não participa diretamente da ação na qual está trocando informações" (2010, p. 4).

É importante ressaltar que a grande quantidade de informação que pode circular nessas conversas e a possibilidade de elas serem mantidas tanto de forma síncrona quanto assíncrona podem dificultar o acompanhamento das mesmas. Portanto, os próximos mecanismos - de coordenação e de percepção - são complementares ao de conversação.

\subsection{Mecanismos de Coordenação}

Uma atividade colaborativa requer uma demanda grande de organização. Para isso, são necessários o desenvolvimento e a implementação de representações que permitam coordenar pessoas durante a realização do trabalho colaborativo (PREECE; ROGERS; SHARP, 2005). Por essas representações podem-se entender, por exemplo, calendários, cronogramas, e repositórios de arquivos online. As autoras destacam que, para a utilização correta dessas ferramentas, convenções de uso precisam ser estabelecidas, portanto, o design do sistema deve ser feito de forma a ser socialmente aceitável para as pessoas. Ou seja: a interface deve considerar formas de coordenar seus diversos usuários, sem passar a impressão de estar controlando-os.

Os calendários podem, por exemplo, possibilitar o agendamento de encontros virtuais. Esse é um mecanismo de coordenação interessante para evitar a frustração causada pela ausência 
de resposta imediata em discussões online, conforme sugere Sitzmann, Ely e Wisher (2008). A figura 2 apresenta partes da ferramenta Google Calendar, que permite marcar hora inicial e final de um evento, inserir anexos, adicionar convidados, etc. O criador do evento pode também solicitar o envio de lembretes e determinar quando e com que frequência estes serão enviados.

Figura 2 - calendário do Google

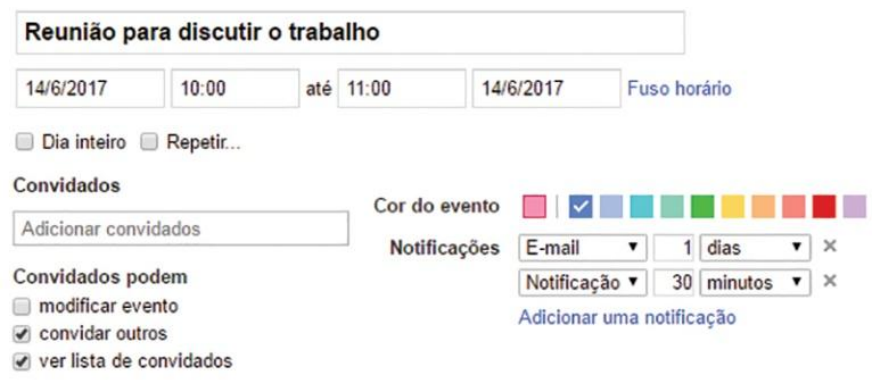

Fonte: evento simulado pela autora no GoogleCalendar.

São algumas das possibilidades de coordenação, segundo Barros (1994, p. 52): "acesso à leitura ou escrita de arquivo, a conexão do indivíduo com o ambiente, o pedido de direito de acesso a um documento, a criação de um novo documento ou sua saída do ambiente". Um exemplo são os grupos do site Facebook, onde se podem identificar alguns mecanismos de coordenação, tais como: envio de arquivos, pesquisa por tópicos, habilitação e desabilitação de notificações, adição de novos membros (e exclusão, para administradores), criação de enquetes e caixas de comentários para as publicações. Essa constatação é importante para a percepção de que funcionalidades dos sites de redes sociais podem ser absorvidas pelas demais interfaces que pretendam alcançar algum nível de colaboração.

Outro mecanismo de coordenação importante é o de busca. Segundo Peters (2013), a interface deve permitir que se grave, arquive, revise e analise os conteúdos de forma acessível. Por isso, a autora ressalta que esses arquivos devem ser facilmente encontrados através de sistemas de busca. Para Krug (2008), a menos que a interface seja simples e de pouco conteúdo, usuários tendem a pesquisar ao invés de navegar pelo site, a fim de ir diretamente ao ponto que procuram. Alguns sites disponibilizam diversos filtros para a busca, como imagens, vídeos, publicações mais populares ou mais recentes, etc. Assim, o usuário pode ter vários tipos de entradas sobre uma mesma informação.

\subsection{Mecanismos de Percepção}

A percepção tem relação com o tópico anterior, porém refere-se a como os usuários notam o desempenho dos outros usuários no sistema. Para isso, a interface deve apresentar elementos que contenham informações referentes às atividades realizadas. Para Gerosa, Fuks e Lucena (2001, p. 114), "o projetista de ambientes virtuais deve prever quais informações de percepção são relevantes, como elas podem ser geradas, onde elementos de percepção serão necessários e de que forma apresentar estes elementos".

Campos et al (2003) ressaltam que, tendo em vista que um dos principais problemas do trabalho em grupo é o da má distribuição de tarefas (uns trabalham mais, outros menos), é importante que, mesmo em um ambiente coletivo, os esforços possam ser avaliados de forma 
individual. Assim, se incentiva a responsabilidade de cada um com o projeto. Um sistema bem projetado pode utilizar-se de vários recursos para facilitar essa avaliação, indicando qual usuário fez qual contribuição, quando e onde encontrá-la, e apresentando-o de forma clara (GEROSA; FUKS; LUCENA, 2001). Quando um documento está sendo editado por mais de um indivíduo na plataforma Google Docs, por exemplo (figura 3), a interface revela - em tempo real - quais usuários estão com o documento aberto e em que linha exata estão trabalhando. Além de facilitar a percepção, esse recurso evita que dois ou mais usuários façam alterações na mesma parte do documento.

Figura 3 - edição online e em conjunto de documento

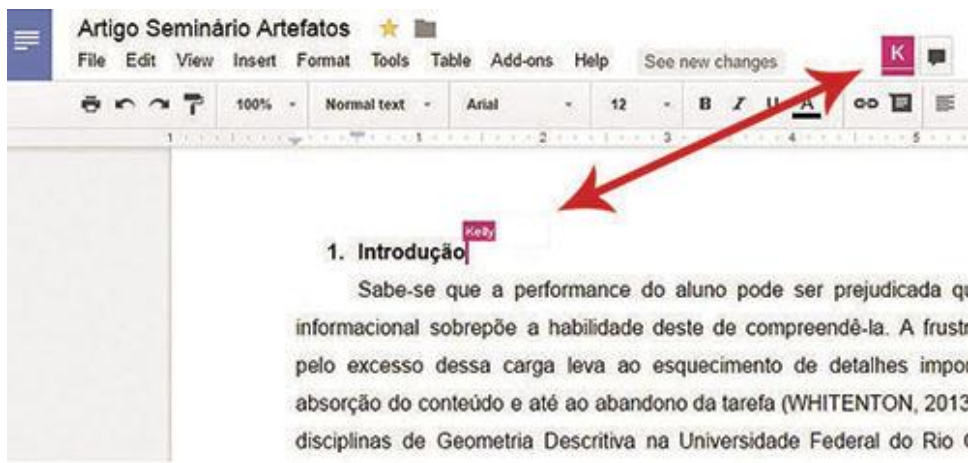

Fonte: tela do GoogleDocs, extraída pela autora.

Recursos como este podem servir como motivação para os demais usuários, que estarão cientes de que podem acompanhar o desempenho de todos e terem seu desempenho acompanhado. Para Clark e Mayer (2016), é importante a criação de estruturas que promovam a responsabilização e a participação individual em um grupo. Gerenciadores de tarefas costumam utilizá-los, normalmente no âmbito empresarial, como o Trello e o Asana ${ }^{3}$. Eles apresentam uma espécie de histórico que registra as alterações, a data, o horário e o nome do usuário que as realizou, além de explicitar os prazos e a quantidade de tarefas. Desta forma, "há menos ênfase em monitorar e ser monitorado e mais em explicitamente deixar que os outros saibam o que está acontecendo" (PREECE; ROGERS; SHARP, 2005, p. 147).

A questão da percepção do trabalho do outro ao se utilizar o meio digital como suporte faz com que a ausência da comunicação face-a-face ${ }^{4}$ seja salientada por diversos autores. A menos que o sistema forneça esse feedback, dificilmente os usuários saberão, em tempo real, se e com o quê o colega está trabalhando. Para Katherine McWhaw et al (2003), no contexto da aprendizagem, o registro de atividades não é somente uma forma de fornecer uma avaliação quantitativa do trabalho para o professor ou tutor; ela também incentiva uma dinâmica ativa de grupo, onde todos podem avaliar seu trabalho e o dos demais.

Quando os alunos aprendem a assumir a responsabilidade de desenvolver experiências de aprendizagem colaborativa motivadoras e eficazes para si próprios e para os membros do seu grupo, eles estarão no seu caminho para se tornar verdadeiros alunos auto orientados (p. 83).

\footnotetext{
${ }^{3}$ Disponíveis para uso mediante cadastro nos sites <https://trello.com> e < https://asana.com/pt/>.

${ }^{4}$ Mesmo em videoconferências, autores relatam que a interação não é equivalente à face-a-face.
} 
Para Crumlish e Malone (2009, p. 162), algumas estratégias visuais podem ser utilizadas para que a presença de um usuário seja declarada aos outros usuários:

- Publicando informações de presença (por exemplo, a data e horário em que o usuário esteve online pela última vez).

- Exibindo um status de presença atual (online/offline).

- Exibindo uma linha do tempo com as últimas atualizações.

- Apresentando um histórico geral de presenças.

- Fornecendo aos usuários uma maneira de serem avisados quando alguém ficar online.

- Fornecendo aos usuários uma maneira de filtrar as atualizações, recebendo somente avisos de seu interesse.

Peters (2013) salienta a importância de reservar uma área na interface na qual os usuários possam preencher com seus perfis, gerando uma maior confiabilidade entre os membros, possibilitando a autoafirmação e a conexão entre usuários com interesses similares. Para a autora, usuários "invisíveis" podem prejudicar a colaboração, pois tornam difícil o reconhecimento entre os membros. No entanto, a autora salienta que o usuário deve ter a liberdade de escolher a privacidade e o conteúdo de suas fotos. Segundo Crumlish e Malone (2009, p. 81): "o núcleo em torno do qual os sites sociais giram são as pessoas: quem elas são, como você as conhece, como elas estão contribuindo. As pessoas, a forma como se apresentam e suas contribuições tornam uma comunidade rica e unida".

As características acima descritas evidenciam os variados aspectos nos quais se pode possibilitar a colaboração através da escolha de ferramentas adequadas e apresentadas de forma coerente nas interfaces.

\section{Identificação das Necessidades}

Essa seção apresenta uma listagem de necessidades de interface para facilitar a colaboração em ambientes virtuais de aprendizagem. Em termos metodológicos, cabe dizer que os dados apresentados foram identificados nos textos consultados na fundamentação teórica em conjunto com uma análise de similares, realizada para verificar como alguns aplicativos e sites aplicam os mecanismos pesquisados. Os similares selecionados não são necessariamente voltados para práticas educacionais, no entanto possuem características que facilitam a colaboração. De acordo com Meurer (2014), a coleta de referências em design digital pode estender-se para qualquer área, independentemente do nicho em questão, considerando que "sítios virtuais, sistemas ou aplicativos com funcionalidades muito distintas podem apresentar características ergonômicas, estruturais e estéticas que representam boas referências para serem analisadas" ( $p$. 118).

O processo utilizado para categorizar as necessidades foi o de "caixas" (BARDIN, 2011), no qual o sistema de categorias já estava pré-estabelecido: as funcionalidades identificadas foram distribuídas a partir dos três mecanismos citados por Preece, Rogers e Sharp (2005), de conversação, de coordenação e de percepção (figura 4).

Figura 4 - funcionalidades distribuídas entre os mecanismos de colaboração 


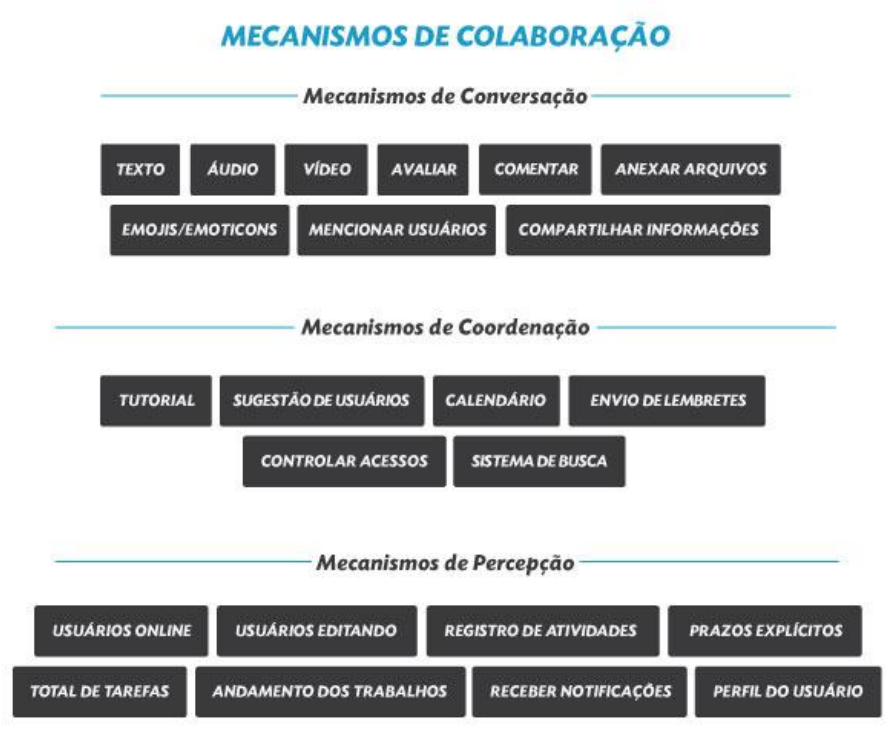

Fonte: criado pela autora.

Após a distribuição, a fim de converter as funcionalidades pesquisadas em necessidades, foi utilizada uma técnica de captura apontada nos estudos do Centro de Engenharia e Design da Universidade de Cambridge ${ }^{5}$, de forma adaptada, que considera o papel do usuário, a sua necessidade e a razão daquela necessidade. Sendo a origem das necessidades os autores consultados na fundamentação, foi utilizado o seguinte modelo: mecanismo + necessidade + razão.

\subsection{Listagem de Necessidades}

A partir dos procedimentos citados foram identificadas 16 necessidades, evidenciando a importância da existência dos mecanismos de colaboração nas interfaces, de forma a facilitar a ação colaborativa e proporcionar a satisfação do usuário em relação às funcionalidades do ambiente virtual. A listagem encontra-se abaixo, no quadro 2, constando, na primeira coluna, o mecanismo, na segunda, a necessidade, na terceira, a justificativa e nas seguintes o (os/as) autor (es/as) consultado na revisão bibliográfica e o similar analisado.

Quadro 2 - listagem de necessidades

\begin{tabular}{|c|c|c|c|c|}
\hline Mecanismo & Eu necessito... & Para que eu possa... & Autor (a) & Similar \\
\hline \multirow[t]{4}{*}{ Conversação } & $\begin{array}{l}\text { De suporte a conversa tanto por } \\
\text { texto, quanto por áudio e vídeo }\end{array}$ & $\begin{array}{l}\text { Conversar de acordo com a } \\
\text { necessidade comunicacional } \\
\text { do momento (mais rápido, } \\
\text { mais claro, mais pessoal, etc.) }\end{array}$ & Horton (2011) & $\begin{array}{l}\text { Facebook } \\
\text { Whatsapp } \\
\text { Skype }\end{array}$ \\
\hline & $\begin{array}{l}\text { De áreas para avaliar ou } \\
\text { comentar o conteúdo publicado }\end{array}$ & $\begin{array}{l}\text { Me manter ativo e crítico em } \\
\text { relação aos conteúdos }\end{array}$ & $\begin{array}{l}\text { Oliveira e Lima } \\
\text { (2011) }\end{array}$ & $\begin{array}{l}\text { Edmodo } \\
\text { Facebook }\end{array}$ \\
\hline & $\begin{array}{l}\text { (ex.: rankings, reações, caixas de } \\
\text { comentários) }\end{array}$ & $\begin{array}{l}\text { compartilhados ou } \\
\text { publicados }\end{array}$ & Peters (2013) & \\
\hline & De suporte a anexo de arquivos e & Compartilhar arquivos & Preece, Rogers e & Facebook \\
\hline
\end{tabular}

\footnotetext{
${ }^{5}$ Disponível em: <http://www.inclusivedesigntoolkit.com/GS_explore/explore.html\#needs>. Acesso em: 6 jul. 2017.
} 


\begin{tabular}{l} 
imagens \\
\hline $\mathrm{Da}$ possibilidade de inserir \\
emojis/emoticons
\end{tabular}

emojis/emoticons

Da possibilidade de mencionar um usuário específico em uma conversa ou comentário

Da opção de compartilhamento de informação publicada imagens facilmente com meus contatos

Expressar minhas emoções em relação aos conteúdos sem necessariamente ser visto

Notificar um usuário
específico em um grupo, a fim de receber um retorno mais rapidamente ou delegar uma tarefa

Trocar informações que podem ser de interesse geral ou de outro usuário

Compreender de que forma posso colaborar com meus colegas

Facilitar a conexão com usuários com os mesmos interesses ou dos mesmos grupos

Calendário com suporte para marcar reuniões e enviar lembretes sobre os eventos

Organizar uma agenda com compromissos e lembrar dos mesmos

\begin{tabular}{ll} 
Sitzmann, Ely e & Google \\
Wisher (2008) & Calendar \\
Preece, Rogers e & \\
Sharp (2005) & \\
\hline Barros (1994) & Facebook
\end{tabular}

\begin{tabular}{llll}
\hline Possibilidade de definir quem & Dividir tarefas entre grupos & Barros (1994) & Facebook \\
tem acesso ou pode visualizar & fechados & &
\end{tabular}
determinada área

\begin{tabular}{lllll}
\hline $\begin{array}{l}\text { Sistema de busca com opções de } \\
\text { refinamento }\end{array}$ & $\begin{array}{l}\text { Encontrar } \\
\text { compartilhados }\end{array}$ & conteúdos & Peters (2013) & Twitter \\
& rapma & Krug (2008) &
\end{tabular}
rápida a partir do nome do arquivo, do usuário, do tipo etc.

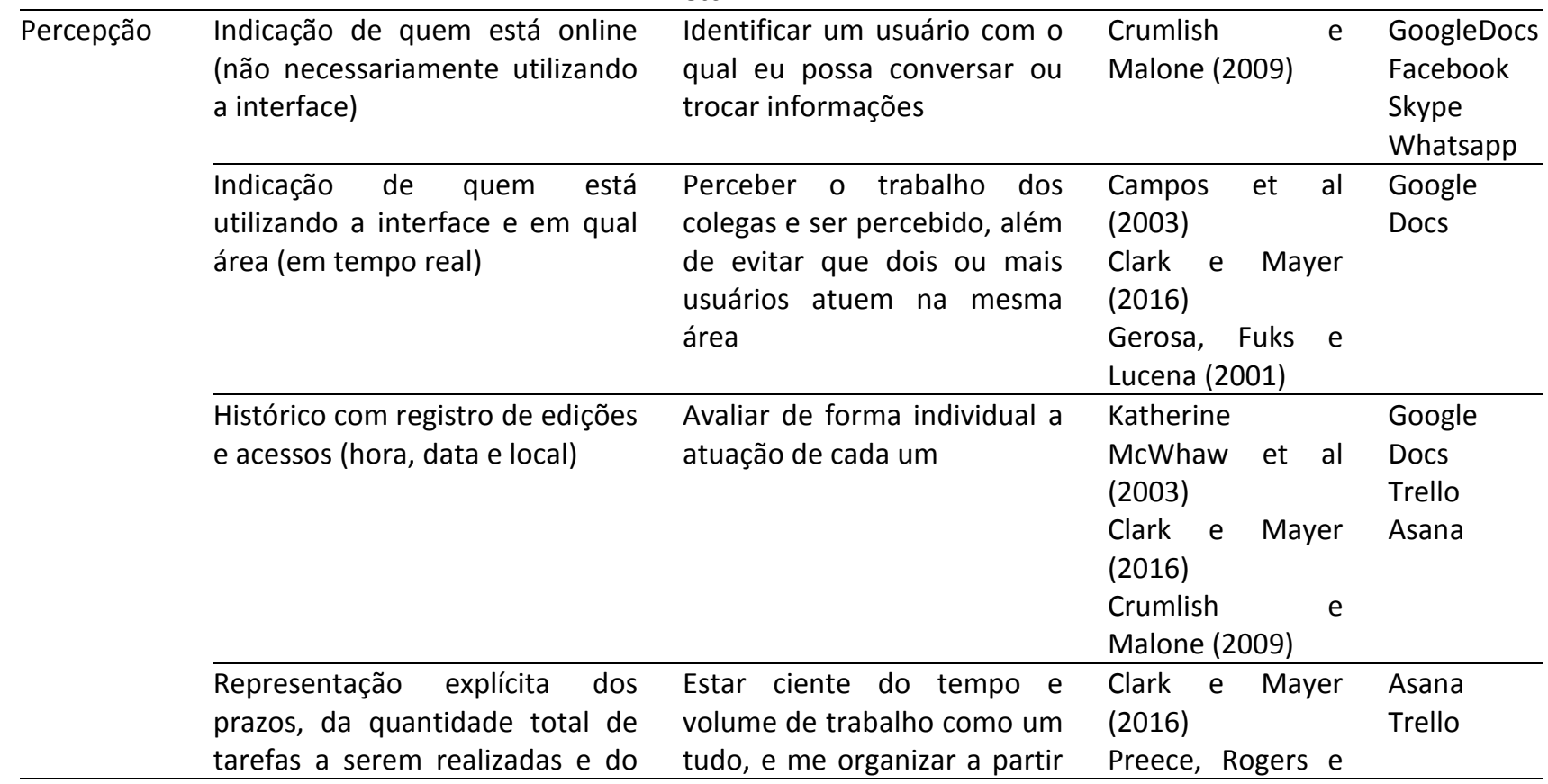


andamento dos trabalhos

Receber notificações quando alguém está online ou altera os conteúdos compartilhados

Área para preenchimento do perfil do usuário (com fotos) dessas informações

Acompanhar 0 andamento

dos trabalhos a qualquer momento

Conhecer e ser conhecida por meus colegas; sentir uma maior confiança quanto à pessoa que está "do outro lado"
Sharp (2005)

$\begin{array}{lll}\begin{array}{l}\text { Crumlish } \\ \text { Malone (2009) }\end{array} & \text { e } & \begin{array}{l}\text { SmartSheet } \\ \text { Trello }\end{array} \\ \begin{array}{lll}\text { Crumlish } \\ \text { Malone (2009) } \\ \text { Peters (2013) }\end{array} & & \\ & & \\ & & \\ \end{array}$

Fonte: desenvolvido pela autora.

\section{Conclusão}

A influência das tecnologias digitais no dia-a-dia dos indivíduos é cada vez mais evidente; Manuel Castells, já em 2003, salientou que a internet havia se tornado "uma extensão da vida como ela é, em todas as suas dimensões e sob todas as suas modalidades" (2003, p. 100). Esse fator transformou não só a forma como as pessoas se relacionam, vivem, e trabalham, mas também como se informam e aprendem. É importante acompanhar essas novas tendências nos mais variados espaços e, dentre as diversas vertentes em que o design pode auxiliar nessa adaptação, este artigo focou na colaboração entre usuários de ambientes virtuais de aprendizagem.

A fim de iniciar uma reflexão sobre como projetar interfaces que facilitem a colaboração entre usuários, procurou-se, em um primeiro momento, identificar elementos gráficos e ferramentas que auxiliassem esse processo, partindo de uma revisão bibliográfica das áreas de design, educação, comunicação, entre outras. Concomitantemente, foi realizada uma análise de similares onde plataformas que proporcionam ferramentas colaborativas foram exploradas e relacionadas aos conteúdos pesquisados. Esta etapa possibilitou visualizar de que forma o projeto de uma interface pode contribuir para que a colaboração entre seus usuários ocorra de forma facilitada, tendo como principal referência os mecanismos de colaboração, elucidados por Preece, Rogers e Sharp (2005).

Não se pretende aqui afirmar que basta o desenvolvimento das necessidades identificadas na pesquisa para que ocorra a colaboração em AVAs; não apenas os recursos apresentados em uma interface implicam nesta questão, sendo possível encontrar outras variáveis. $O$ que se procurou foi esclarecer algumas das formas pelas quais o design da interface pode facilitar que 0 processo colaborativo ocorra; formas que devem vir acompanhadas de outras iniciativas e propostas.

Por fim, o trabalho realizado pretendeu contribuir para evidenciar a importância de atividades e experiências colaborativas no planejamento e projeto de ambientes virtuais de aprendizagem, e apresentar alguns dos caminhos possíveis de serem seguidos por designers instrucionais e/ou de interface.

\section{Referências}

ALARCON, Dafne; SPANHOL, Fernando José. Gestão do conhecimento na educação a distância: práticas para o sucesso. São Paulo: Pimenta Cultural, 2015.

ALVES, Alessandra Maria; BARBOSA, Ricardo Rodrigues. Colaboração e compartilhamento da 
informação no ambiente organizacional. In: Encontro Nacional de Pesquisa em Ciência da Informação. 6 . Rio de Janeiro, 2010.2 Disponível em: <http://enancib.ibict.br/index.php/enancib/xienancib/paper/viewFile/3468/2593>. Acesso em: 02 ago. 2017.

ASSOCIAÇÃO BRASILEIRA DE EDUCAÇÃO A DISTÂNCIA. Relatório analítico da aprendizagem a distância no Brasil $\quad$ - $2016 . \quad$ Disponível em: < http://abed.org.br/censoead2016/Censo_EAD_2016_portugues.pdf> Acesso em: 14 mar. 2018.

BARDIN, Laurence. Análise de conteúdo. São Paulo: Edições 70, 2011.

BARROS, Lígia. Sistemas de Suporte a Ambientes Distribuídos para Aprendizagem Cooperativa. Rio de Janeiro. 1994. 208 p. Tese de Doutorado - Engenharia de Sistemas e Computação, Universidade Federal do Rio de Janeiro.

BOTSMAN, Rachel; ROGERS, Roo. 0 que é meu é seu: como o consumo colaborativo vai mudar o nosso mundo. São Paulo: Bookman, 2009.

BÜRDEK, Bernhard. Design: história, teoria e prática do design de produtos. São Paulo: Blücher, 2010.

CAMPOS, Fernanda et al. Cooperação e aprendizagem on-line. Rio de janeiro: DP\&A, 2003.

CARDOSO, Teresa; MATOS, Filipa. Aprender línguas estrangeiras no século XXI: teletandem através do skype. Educação, Formação \& Tecnologias, Monte da Caparica, v. 5, n. 2, p. 85-95, 2012.

CASTELLS, Manuel. A Galáxia Internet: reflexões sobre a Internet, negócios e a sociedade. Zahar, 2003.

CAVALCANTI, Carolina. Design Thinking como metodologia de pesquisa para concepção de um Ambiente Virtual de Aprendizagem centrado no usuário. In: SIMPÓsIO INTERNACIONAL DE EDUCAÇÃO A DISTÂNCIA, 2014, São Carlos. Disponível em: <http://www.siedenped2014.ead.ufscar.br/ojs/index.php/2014/article/view/518/237>. Acesso em: 02 ago. 2017.

CLARK, Ruth; MAYER, Richard. E-learning and the science of instruction: Proven guidelines for consumers and designers of multimedia learning. New Jersey: John Wiley \& Sons, 2016.

CRUMLISH, Christian; MALONE, Erin. Designing social interfaces: Principles, patterns, and practices for improving the user experience. Sebastopol: O'Reilly Media, 2009.

DIAS, Paulo. Inovação pedagógica para a sustentabilidade da educação aberta e em rede. Educação, Formação \& Tecnologias, Monte da Caparica, v. 6, n. 2, p. 4-14, 2013.

FILATRO, Andrea; CAIRO, Sabrina. Produção de conteúdos educacionais. São Paulo: Saraiva, 2015.

GEROSA, Marco Aurélio; FUKS, Hugo; LUCENA, Carlos José Pereira. Elementos de percepção como forma de facilitar a colaboração em cursos via Internet. In: SIMPÓsIO BRASILEIRO DE INFORMÁTICA NA EDUCAÇÃO, 2001, Vitória. p. 194-202. Disponível em: $<$ http://groupware.les.inf.puc-rio.br/public/papers/Percepcao_SBIE.pdf>. Acesso em: 28 ago 2017.

HAMUY, Eduardo; GALAZ, Mirtha. Information versus communication in course management system participation. Computers \& Education, v. 54, n. 1, p. 169-177, 2010.

HORTON, William. E-learning by design. New Jersey: John Wiley \& Sons, 2011. 
HRON, Aemilian; FRIEDRICH, Helmut . A review of web-based collaborative learning: factors beyond technology. Journal of Computer Assisted Learning, v. 19, n. 1, p. 70 - 79, 2003.

IMRAN, Ali Shariq et al. An Analysis of Social Collaboration and Networking Tools in eLearning. In: ZAPHIRIS, Panayiotis; IOANNOU, Andri. Learning and Collaboration Technologies. Toronto: Springer, 2016.

LEMOS, André; LÉVY, Pierre. O futuro da internet: em direção a uma ciberdemocracia planetária. São Paulo: Paulus, 2010.

LÉVY, Pierre. Cibercultura. 3. ed. São Paulo: Ed.34, 2010.

LOWYCK, Joost; PÖYSÄ, Johanna. Design of collaborative learning environments. Computers in human behavior, v. 17, n. 5, p. 507-516, 2001.

MANZINI, Ezio. Design para a inovação social e sustentabilidade: comunidades criativas, organizações colaborativas e novas redes projetuais. Rio de Janeiro: E-papers, 2008.

MATTAR, João. Design educacional: educação a distância na prática. São Paulo: Artesanato Educacional, 2014.

MCWHAW, Katherine et al. From co-operation to collaboration. Helping students become collaborative learners. In: ASHMAN, Adrian; GILLIES, Robyn. Cooperative learning: The social and intellectual outcomes of learning in groups. New York: Routledge, p. 69-86, 2003.

MEURER, Heli. Ferramenta de gerenciamento e recomendação como recurso na aprendizagem baseada em projeto de design. 246f. 2014. Tese (Doutorado em Informática na Educação) Centro de Estudos Interdisciplinares em Novas Tecnologias na Educação, Universidade Federal do Rio Grande do Sul, Porto Alegre, 2014.

OLIVEIRA, Márcia; LIMA, Valéria. O estudante da EaD: seu papel e sua organização para o estudo. In: OTSUKA, Joice Lee et al. Educação a distância: formação do estudante virtual. São Carlos: UFSCar, 2011. p. 59-72.

PALFREY, John Gorham; GASSER, Urs. Nascidos na era digital: entendendo a primeira geração de nativos digitais. Artmed, 2011.

PETERS, Dorian. Interface design for learning: design strategies for learning experiences. London: Pearson Education, 2013.

PORTUGAL, Cristina. Design, educação e tecnologia. Rio de Janeiro: Rio Books, 2013.

PREECE, Jenny; ROGERS, Yvonne; SHARP, Helen. Design de interação. São Paulo: Bookman, 2005.

PRIMO, Alex et al. Conversações fluidas na cibercultura. In: Encontro Anual da Compós, 15., 2016, Goiânia: Universidade Federal de Goiás, 2016.

SILVA, Robson. Moodle para gestores autores e tutores 3. São Paulo: Novatec, 2016.

SITZMANN, Traci; ELY, Katherine; WISHER, Robert. Designing Web-Based Training Courses to Maximize Learning. In: ORVIS, Kara; LASSITER, Andrea. Computer-Supported Collaborative Learning: Best Practices and Principles for Instructors. London: IGI Global, 2008.

TRONCARELLI, Marcella Zampoli; FARIA, Adriano Antonio. A aprendizagem colaborativa para a interdependência positiva no processo ensino-aprendizagem em cursos universitários. Educação, 
Santa Maria, v. 39, n. 2, p. 427-444, 2014. 